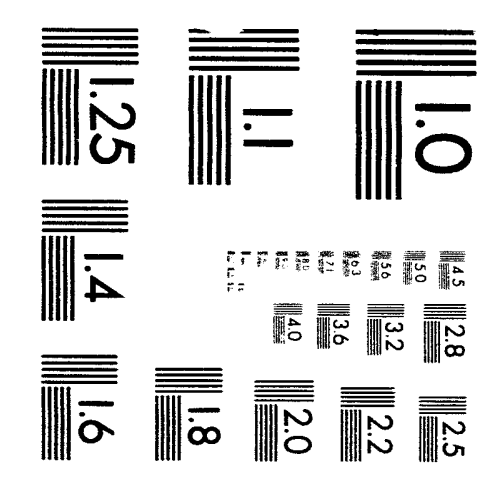



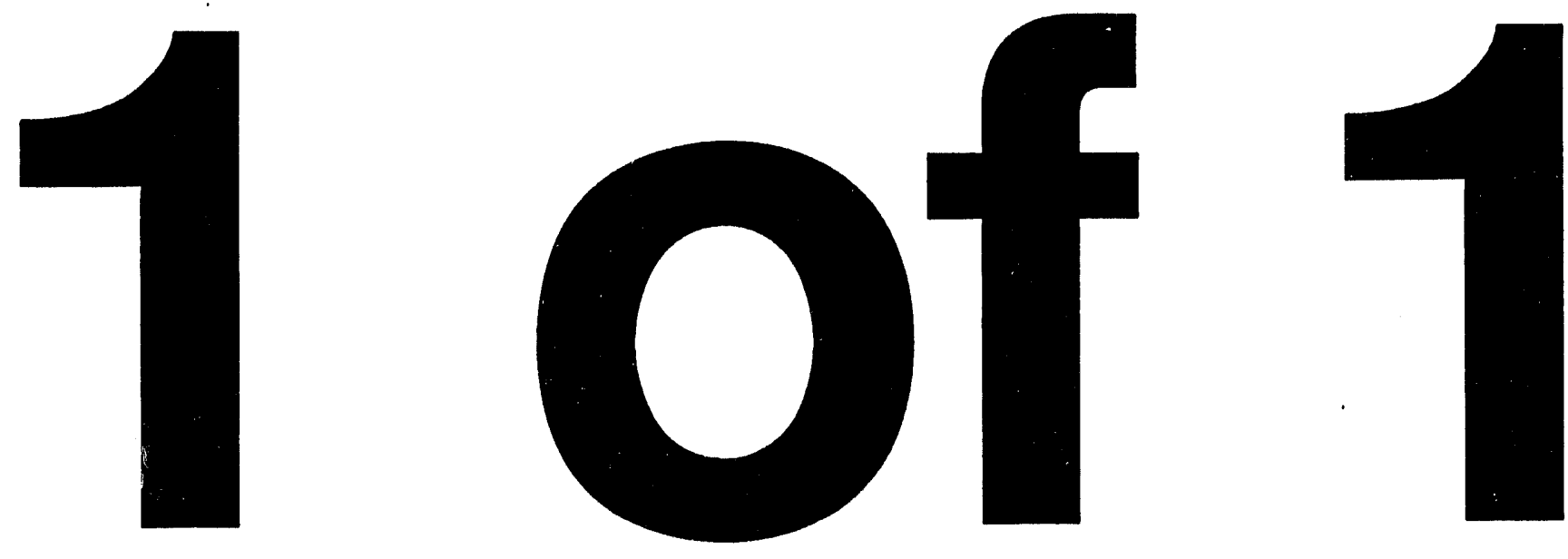


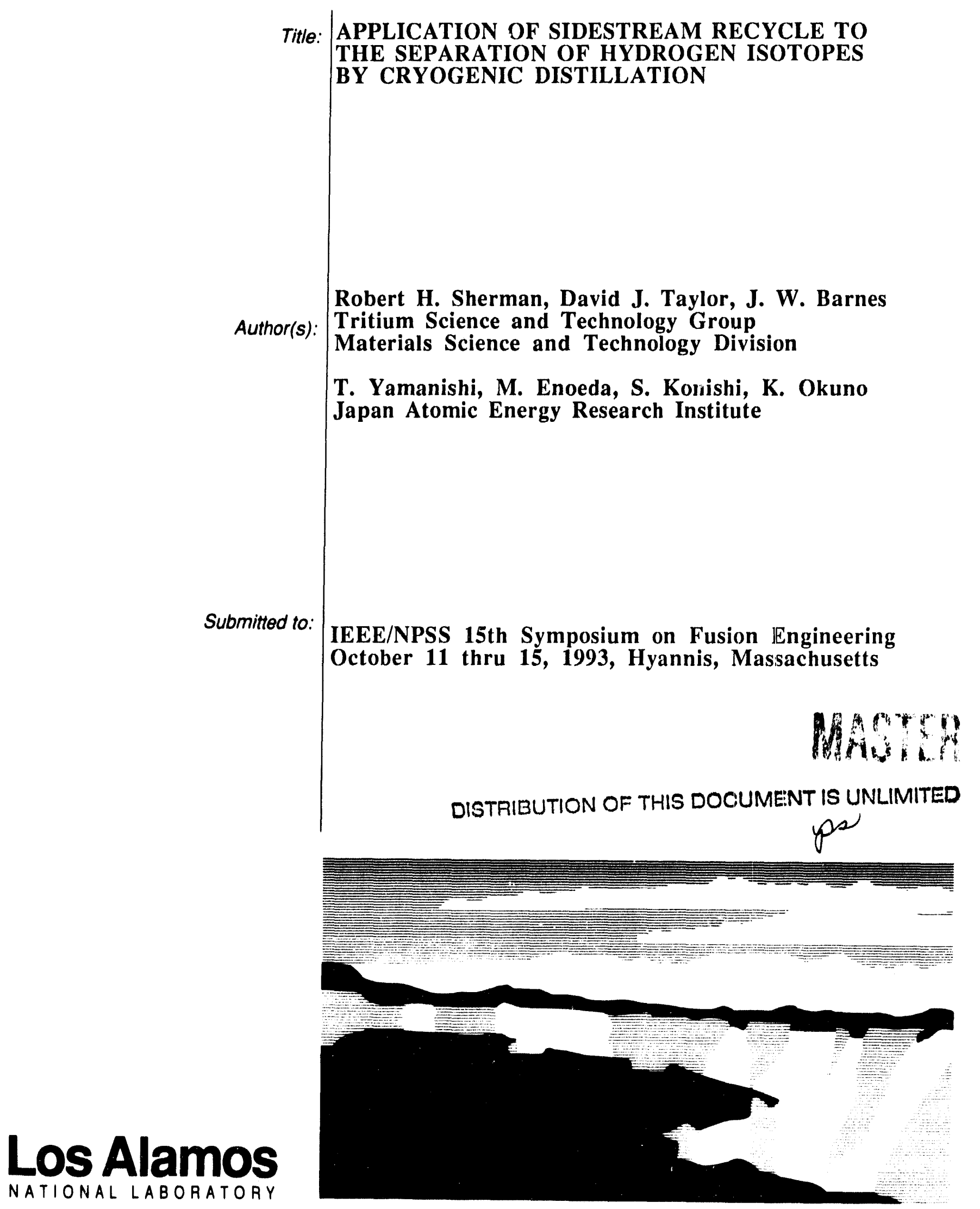

Los Alamos National Laboratory, an atfirmative action/equal opportunity empldyer, is operated by the University of California for the U.S. Department of Energy under contract W-7405-ENG-36. By acceptance of this article, the publisher recognizes that the U.S. Government retains a nonexclusive, royalty-free license to publish or reproduce the published form of this contribution, or to allow others to do so, for U.S. Government purposes. The Los Alamos National Laboratory requests that the publisher identify this article as work performed under the auspices of the U.S. Department of Energy. 


\title{
Application Of Sidestream Recycle To The Separation Of Hydrogen Isotopes By Cryogenic Distillation
}

\author{
Robert H. Sherman, David J. Taylor, and J. W. Barnes \\ Tritium Systems Test Assembly, Los Alamos National Laboratory \\ MS-C348, P.O. Box 1663, Los Alamos, New Mexico 87545, USA \\ and \\ T. Yamanishi, M. Enoeda, S. Konishi, and K. Okuno \\ Japan Atomic Energy Research Institute \\ Tokai-mura, Ibaraki-ken, Japan
}

\begin{abstract}
Withdrawal of a sidestream from an isotopicseparation distillation column followed by equilibration of species and reinjection is a technique for reducing the required number of columns and hence reducing tritium inventories in fusion-energy fuel processing systems. Measurements have been made with a single column and the three-component: $\mathrm{H}_{2}-\mathrm{HD}-\mathrm{D}_{2}$ system withdrawing streams of essentially pure $\mathrm{H}_{2}$ and $\mathrm{D}_{2}$. This was followed by single column measurements with the full HDT system and a column inventory of $c a .16 .8 \mathrm{moles}$ (H/D/T = 0.043/0.528/0.429). Rather pure $T_{2}$ (ca. $98.7 \mathrm{~mol} \%$ ) was produced as one of the products. This would previously have required two separate distillation columns with an inventory of ca. 16 moles of $T_{2}$ as compared with 7.2 moles of $T_{2}$ in these experiments. The dynamic response of the $H-D$ system was followed using in-situ laser Raman spectroscopy to obtain product compositions and column composition profiles.
\end{abstract}

\section{INTRODUCTION}

Normally one cryogenic distillation column is required for each specified component to be extracted as a product from a distillation column system. Withdrawal of a sidestream, followed by isotopic equilibration at room temperature, and reinjection into the distillation column is a powerful technique for reducing the required number of columns and hence reducing tritium inventories with significant application to the processing of fusion fuel streams.[1]

Thus in a $\mathrm{H}-\mathrm{T}$ system, the species equilibrate to $\mathrm{H}_{2}$ HT- $T_{2}$. In a normal column the distillate stream could be chosen to be either $\mathrm{H}_{2}$ or $\mathrm{H}_{2}+\mathrm{HT}$. Correspondingly the reboiler product would be constrained to be $\mathrm{HT}+\mathrm{T}_{2}$ or $\mathrm{T}_{2}$. In either case a significant quantity of tritium in the form of $\mathrm{HT}$ must appear as a product. HT is, in gencral, a rather undesirable molecule as fusion fucl process systems try to eliminate $\mathrm{H}$-bearing species and drastically reduce the amount of T-bearing species which must be treated as waste.
In normal operation the three species vary in concentration from the bottom to the top of the column, with the $\mathrm{T}_{2}$ concentrating at the bottom, the $\mathrm{H}_{2}$ concentrating at the top, and the HT peaking somewhere in the center of the column. If a sidestream is withdrawn from the distillation column at a point where the HT species is near a maximum and passed over a catalyst bed, the isotopic equilibrium,

$$
2 \mathrm{HT} \Leftrightarrow \mathrm{H}_{2}+\mathrm{T}_{2},
$$

is effected and the HT molecule is reduced, increasing the $\mathrm{H}_{2}$ and $T_{2}$ species which, after reiniroduction into the crlumn, will appear at the top and bottorn, respectively. Composition profiles are shown in Figs. $I$ anci 2 for the $\mathrm{H}_{2}-\mathrm{HD}-\mathrm{D}_{2}$ system, without and with sidestream recy $\mathrm{lc}$, as predicted by dynamic modeling.

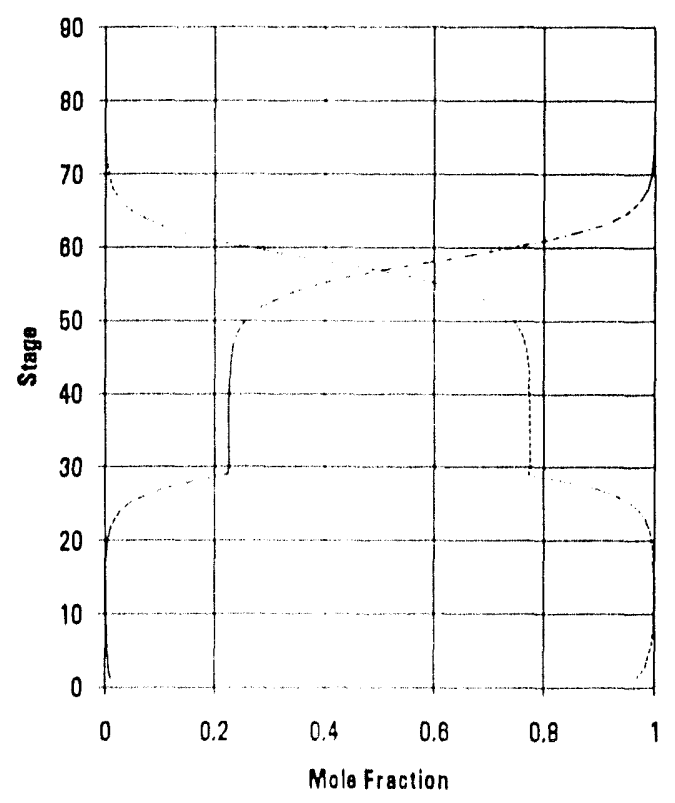

Fig. I Equilibrium Composition Profile 13LFORE sidestream recycle. Feed is at stage 29. Dashed line - $H_{2,}$, dotted line III), Solid line- $D_{2}$ (lower-left comer of figure). 
Utilizing this approach it is possible to reduce the number of columns required by a factor of as much as two. This will permit a significant reduction in the inventory of tritium held up in the distillation system as well as the complexity and controllability of the overall system, especially in a full HDT isotope separation system.

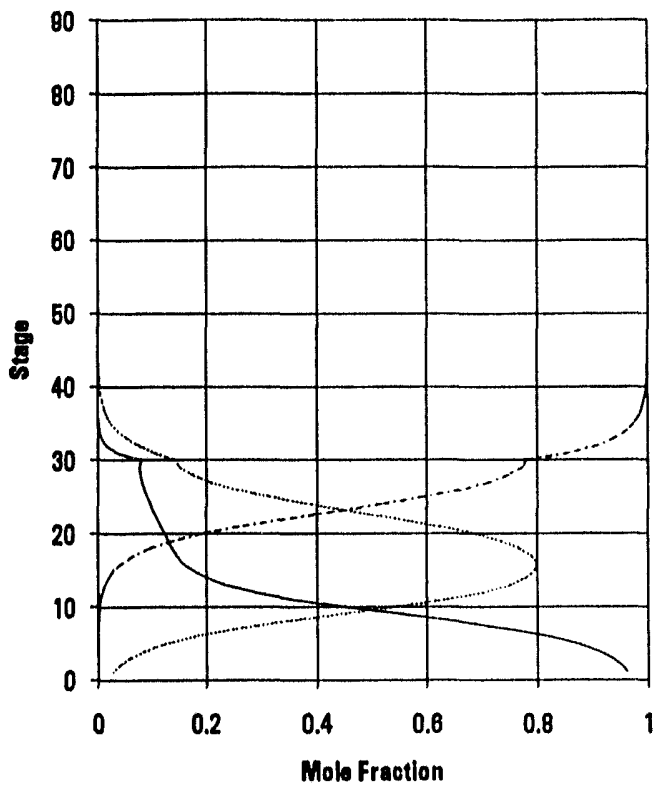

Fig. 2 Equilibrium Composition Profile WITH sidestream recycle. Feed is at stage 29, sidestream recycle is from stage 9 to stage 29. Dashed line $-\mathrm{H}_{2}$, dotted line $\mathrm{HD}$, Solid line $-\mathrm{D}_{2}$ (lower-left comer of figure).

\section{EXPERIMENTAL}

\section{A. Experiments with $\mathrm{H}_{2}$ and $\mathrm{D}_{2}$}

For this research, the $\mathrm{H}_{2}-\mathrm{HD}-\mathrm{D}_{2}$ system was chosen for initial study. The first column of the TSTA (Tritium Systems Test Assembly) 4-column cascade was chosen for the tests because it has 84 theoretical stages, 3 alternate feedinjection points, and seven sample withdrawal locations.[2] The column process piping was modified to permit a stream to be withdrawn from any of the sample taps through a flow control valve, equilibrated over a precious metal catalyst bed at ambient temperature, aild pumped back into any other sample tap. Fig. 3 shows the column layout schematically.

The column was cooled to $c a .20 \mathrm{~K}$ and filled with 14.2 moles of a hydrogen isotopic mixture with the composition $\mathrm{H}: \mathrm{D}=2: 1$. Approximately $0.002 \%$ of $\mathrm{T}_{2}$ was eluted from the walls of the system during the course of the measurements, but this had no significant effect on the performance of the system. Tritium appeared as HT or DT in the top and bottom products.
After a period at total reflux, the top and bottom streams were withdrawn at rates of ca. 2971 and $66 \mathrm{sccm}(\sim$ $2 \%$ ) respectively, recombined and re-injected into the main feed at a rate of ca. $3037 \mathrm{sccm}$. The reflux ratio was 8 . During this time the composition of the various streams were determined by in-situ Raman spectrometry. Raman analyses were taken every two minutes, each observation being the average of 1001 -second scans. After a period of several hours, when the composition had reached a steady state, sidestream recycle was initiated at the rate of $1008 \mathrm{sccm}$ using the withdrawal and reinjection stages illustrated in Fig. 2.. Fig. 4 shows the dynamics observed during a several hour period of Raman measurements of the reboiler (bottom) stream composition with data points taken every minute. The flows chosen are similar to those which might be expected in a system designed to recover $T_{2}$ from an $\mathrm{H}-\mathrm{T}$ breedingblanket system.

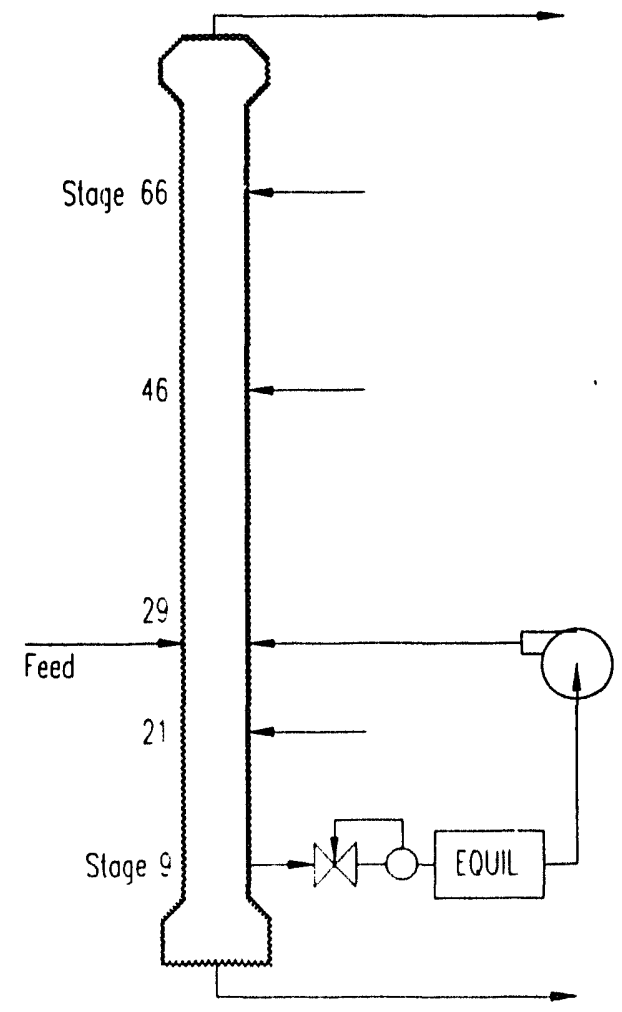

Fig. 3 Schematic diagram of TSTA Column I as modified for sidestream recycle.

After the data in Fig. 4 was obtained, the sidestream recycle flow was stopped and the system allowed to return to normal 1-column operation. A portion of the data taken every 2 minutes over an 8-hour period are shown in Fig. 5.

Following the return to steady state, sidestream recycle was again started. This time the reboiler flow was $184 \mathrm{sccm}(-6 \%)$ and the sidestream recycle flow was 1999 $\mathrm{sccm}$. The dynamics were followed for a period of several hours taking Raman spectra of the reboiler stream every 2 


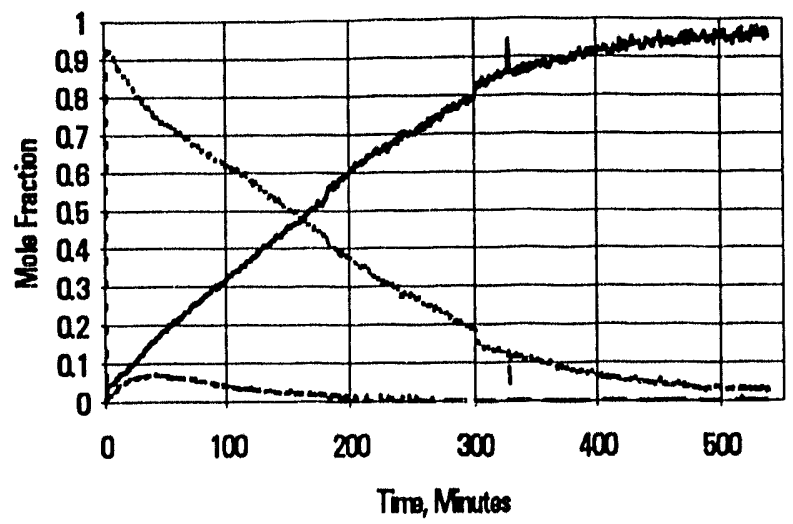

Fig. 4 Reboiler composition following initiation of sidestream recycle (1008 $80 \mathrm{~cm}$ ). Solid line $-D_{2}$, dotted line $H D$, dashed line $-\mathrm{H}_{2}$

minutes. The results are shown in Fig. 6. It was unfortunately necessary to terminate the experiment after only about 5 hours. If this experiment had been allowed to proceed for about 20 hours the reboiler composition must have returned to containing some $\mathrm{HD}$ as dictated by mass balance considerations and predicted by static and dynamic modeling.

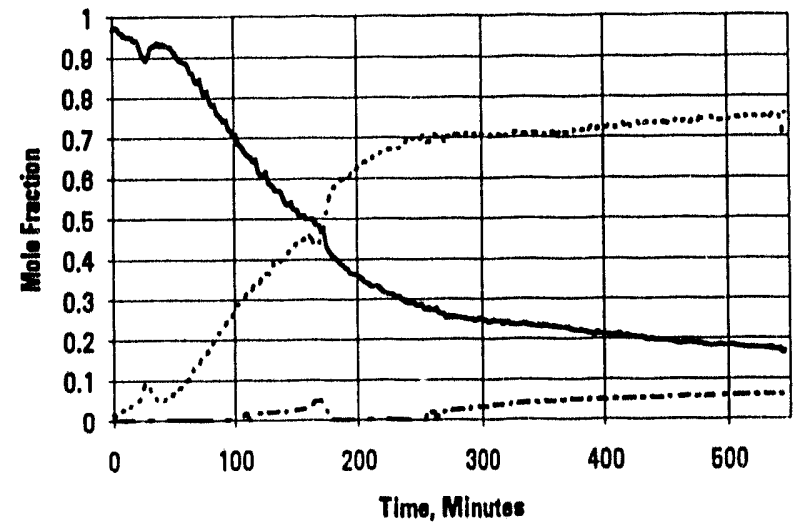

Fig. 5 Reboilcr composition without sidestream reoycle - return to normal single-column operation. Solid line $-\mathrm{D}_{2}$, dotted line $\mathrm{HD}$, dashed line $-\mathrm{H}_{2}$

B. Experiments with $H, D$, and $T$.

A second set of experiments was performed having charged the columns with a 16.8 mole mixture having the composition $H: D: T=0.043: 0.528: 0.429$; a reflux ratio of 8 was used. Because of the requirements to perform other experiments with the TSTA process loop it was not possible to obtain significant dynamic data for the distillation column

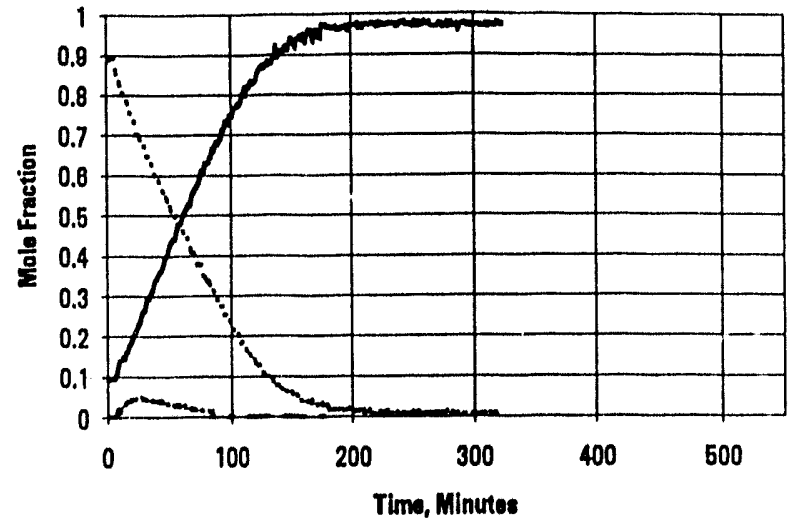

Fig. 6 Reboiler composition following initiation of sidestream recycle (1999 sccm). Solid line $-D_{2}$, dotted line $H D$, dashed line $-\mathrm{H}_{2}$

response. However operating the system in a similar manner to the H-D experiments above it was possible to extract a reboiler stream with a composition of up to $2.6 \% \mathrm{DT}, 97.4 \%$ $T_{2}$, and no significant quantity of $D_{2}$. At the same time the top stream was mostly $\mathrm{HD}$ and $\mathrm{D}_{2}$ with a little $\mathrm{DT}$, having an HDT ratio of $H: D: T=0.21: 0.79: 0.10$. Without sidestream recycle the reboiler composition was $\mathrm{D}_{2}: \mathrm{DT}: \mathrm{T}_{2}=0.078: 0.516: 0.406$.

\section{DISCUSSION}

Without the use of sidestream recycle, it has traditionally been necessary to make use of a 2-column cascade to produce streams of pure $\mathrm{H}_{2}$ and $\mathrm{T}_{2}$ from an $\mathrm{H}_{2}$ HT- $T_{2}$ mixture. Each of the two columns would have a significant inventory of tritium. The use of the sidestream recycle configuration permits the elimination of one distillation column. The column flow rates must be adjusted and the column profile is modified. The resultant tritium inventory is reduced by a factor of almost two.

\section{ACKNOWLEDGMENT}

This work was supported by the U.S. DOE, Office of Fusion Energy and the Japan Atomic Energy Research Institute.

\section{REFERENCES}

[1] W. B. Denton, Private Communication, 1978

[2] R. H. Sherman, "Cryogenic hydrogen isotope distillation for the fusion fuel cycle," Fusion Technology, Vol. 8, pp.2175-2183, September 1985.

\section{DISCLAIMER}

This report was prepared as an account of work sponsored by an agency of the United States Government. Neither the United States Government nor any agency thereof, nor any of their employees, makes any warranty, express or implied, of assumes any legal liability or responsibility for the accuracy, completeness, or usefulness of any information, apparatus, product, or process disclosed, or represents that its use would not infringe privately owned rights. Reference herein to any specific commercial product, process, or service by trade name, trademark, manufacturer, or otherwise does not necessarily constitute or imply its endorsement, recommendation, or favoring by the United States Government or any agency thereof. The views and opinions of authors expressed herein do not necessarily state or reflect those of the United States Government or any agency thereof. 

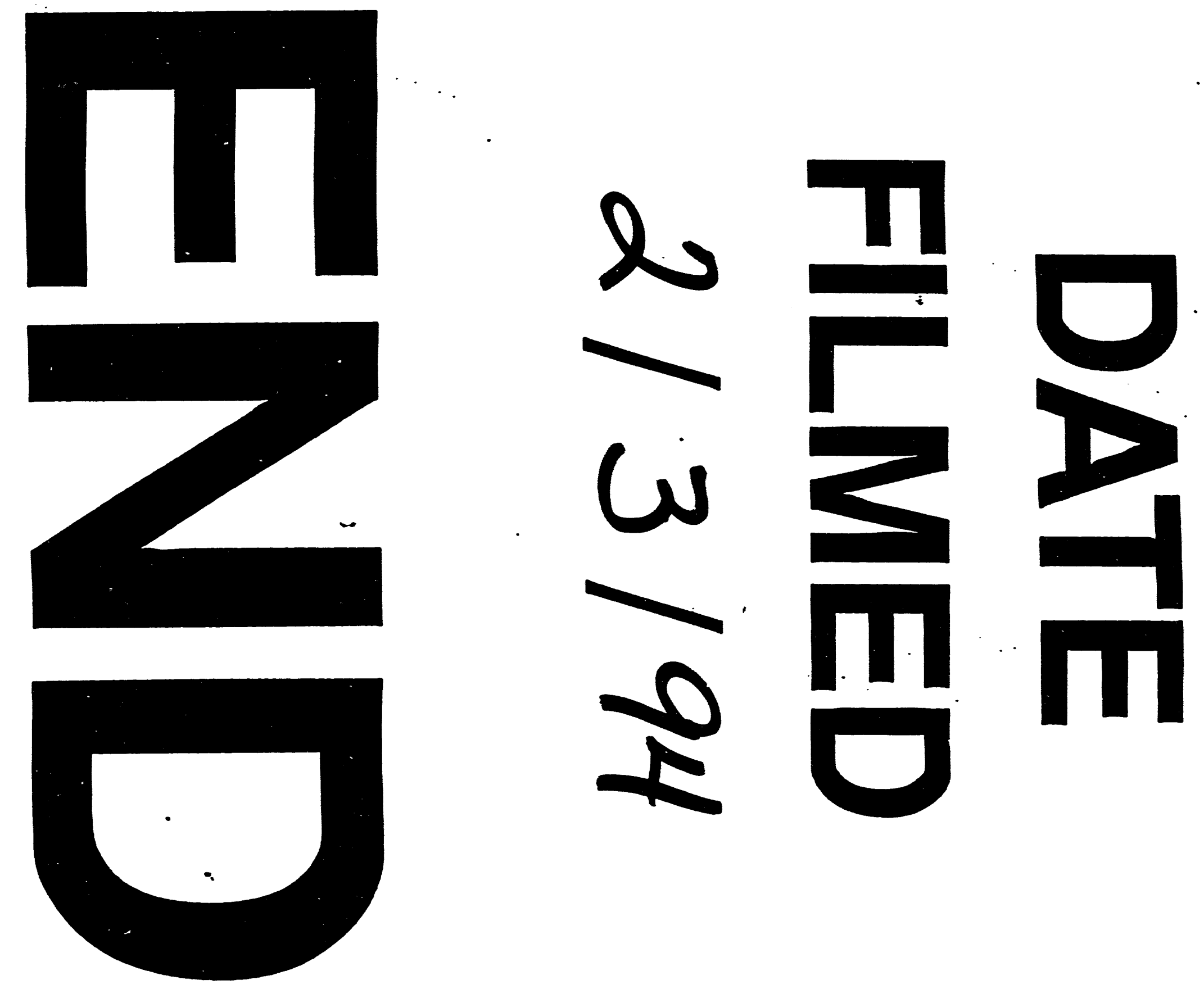
